International Journal of Project Management, Volume 36, Issue 1, 2018, pp. 198-207 DOI:10.1016/j.ijproman.2017.08.003

\title{
When Knowing Is Not Enough: The Role Of Organised Simulations For Developing Effective Practice
}

\author{
Liz Lee-Kelley \\ Cranfield University \\ Cranfield, Bedfordshire, MK43 0AL \\ liz.lee-kelley@cranfield.ac.uk
}




\title{
When 'Knowing What' Is Not Enough: Role of Organised Simulations For Developing Effective Practice
}

\begin{abstract}
A decade on from the Rethinking Project Management (PM) network, concerns about the relevance gap continue with a number of multinationals looking explicitly to alternative strategies and forms of PM staff development. The literature is light on how project simulations can help the development of experienced managers as reflective experts. Few have examined the link between intended learning outcomes and real-time performance. Posing the question of "how easily is knowledge developed in the classroom transformed into effective practice?" the paper presents a chronological account of a 3-day simulated project by 25 experienced managers. Despite their prior experience and learning from shared problem-solving and structured reflections, participants struggled to deliver their projects as planned. Analysis referencing the knowledge epistemology and ambidexterity literatures yielded a number of design improvement opportunities and that closing the knowing-doing gap requires courses to incorporate the 'soft' perceptual and attitudinal aspects underlying why people fail to convert their learning into effective practice.
\end{abstract}

Key words: project education, project simulation, experiential learning, actionable knowledge, reflective practice, ambidexterity.

\section{Executive Summary}

The problem for those of us in management education is that industry remains uncertain about the practical value of academic teaching. This paper examines the extent of classroom learning for 'real-time' problem solving by directly observing an established simulated project. 25 experienced managers participated in 5 teams over 3 days. Simulation results were paradoxical in that all the teams struggled to perform against their own plans. Chronological scrutiny of the data found evidence of learning and knowledge production at both individual and team level. Teams were also able to draw upon their personal \& combined stores of tacit and explicit knowledge to tackle problems early on in the simulation but not after manipulations by the facilitator. 
Further analysis to isolate underlying reasons for the anomaly judged the learning framework for the simulation to be robust and reported a number of design improvements; namely, (1) linking the module-level learning outcomes to the simulation learning cycles, (2) allowing students to repeat the same simulation after a short break, (3) giving project finance greater prominence in the programme and (4) incorporating PM software (such as scheduling, risk and cash management) into the simulation process for quicker updates and help students keep pace with iteration leadtimes. In conclusion, organised simulations are a useful platform for interaction and experiential learning but the transition from merely knowing what to effective practice is personal and complex, requiring further investigation and understanding.

\section{Introduction}

This paper's interest is in the extent to which organised simulations can support practical learning and reflective application by project managers. As projects have become the central mechanism for delivering strategic objectives and organisational benefits, managers are under increasing pressure to be better prepared. The project profession (e.g. APM - Association for Project Management; PMI - Project Management Institute) clearly expects its practitioners to apply their "knowledge, skills, tools and techniques to project activities to meet project requirements" (PMI 2013:554). However, many managers from a variety of non-project disciplines would arrive at their projects with limited prior exposure (Palm and Lindahl 2015). Observations by Cheetham and Chives (2001) and Savelsbergh, Havermans and Storm (2016) noted that professional development for project managers tends to be largely unstructured and emergent. The question of the timing and manner of project management (PM) knowledge and competence development is particularly relevant when organisations juggling between the twin requirement for efficiency and innovation appear uncertain about the value of classroom knowledge. Many organisations are actively seeking alternative strategies to develop their PM staff. For example, BAE, Rolls Royce, Shell, Thales and the UK Ministry of Defence Equipment and Support (DE\&S) have already established some form of in-house PM academy or centre of PM excellence. Instead of automatically releasing their project staff to attend a traditional PM course at a university or further education college, a range of in-house training options are being considered; one of which is the use of experienced practitioner-trainers to prepare managers for certification by a relevant PM professional body. Organisation-specific 
cases are favoured because they allow evaluation and analysis of commercially sensitive problems with a view to producing solutions that are relevant and aligned with the organisation's policy and chosen PM framework. Thales Group's new learning strategy is based on a 70\% ('on the job' experience), 20\% (social learning) and 10\% (traditional education) split. It reflects strongly, industry's reducing reliance on formal PM education. These developments, when juxtaposed against the academic preference for rigorous research and generalizable theories, reveal a persisting gulf between teaching and application in management education (Boyer 1992; Starkey and Madan, 2001).

The Rethinking Project Management initiative did much to promote debate and encourage greater rigour and relevance on PM research and teaching. Two articles drove much of that agenda: (1) Crawford, Morris, Thomas and Winter (2006:624) argued that much of the mainstream learning and development of PM managers fell "short of the reality of ....complex projects"; (2) Winter, Smith, Morris and Cicmil (2006:642) identified the need for learning and development to be capable of facilitating the development of "reflective practitioners who can learn, operate and adapt effectively in complex project environments." The consensus from the Rethinking debate is that experiential learning is a vital part of "our own practice and our own attempts to improve management learning" (Berggren and Söderlund 2008: 287). Just as Schulz (2005) had criticised the social and experiential learning literatures for their silence on the practicality of how learning can be designed and realised quickly by people working in complex and dynamic contexts, Berggren and Söderlund noted the need to examine how to improve PM education. It has been nearly a decade since authors such as Alam, Gale, Brown and Kidd (2008) rated industry-led professional PM development over traditional academic programmes. A quick review of the published brochures and websites of academic institutions offering PM courses found that institutions have worked hard to raise awareness of project complexity and provide a learning environment that is conducive for situated learning and knowledge co-production. Design of courses appear more innovative and contextual, and inductive teaching processes such as case study, role play and simulation are said to be used to support the melding of tacit and explicit knowledge. Yet, as mentioned earlier, the trend in industry is to assume greater control over their staff's professional development. While fully acknowledging the importance of interaction and reflection, the language of organisations and the PM profession continues to revolve around experience and practical competencies. Hence, this paper argues that educators should re-visit their value proposition (Schön 1995) for this highly delivery-centric industry. 
The motivation for the study is the persisting issue of academic relevance. The PM literature has yet to address the question of how higher education PM courses can help managers derive solutions that have true utility in the workplace. In line with the acknowledged role of experiential learning, the context for this research is the simulated project. Although simulations are frequently used in formal education as an immersive tool to encourage sharing and mutual learning (Hallinger and Bridges 2007; Salas, Wildman and Piccolo 2009), close examination of the fit between intended learning outcomes and real-time performance is scant. Posing the question, "how easily is knowledge developed in the classroom transformed into effective practice?" the study reappraises the extent to which formal simulations can create 'actionable knowledge' - a major theme at the 2004 Academy of Management Conference (Cummings and Jones 2006). Target participants are mature project managers who can bring their stores of knowledge from prior experiences to the task (per Dreyfus and Dreyfus 1986 and Cook and Brown 1999). Research at a fine-grained level on the interplay between prior experience, classroom interaction, capability development and application will advance theory and inform teaching practice. The study will also have practical relevance for those involved in supervising, facilitating and undertaking workplace team learning.

In what follows, salient literatures are reviewed and discussed, starting with the axiom that experience, knowledge and learning are inextricably related. This is followed by Cook and Brown's (1999) framework of knowledge epistemologies to determine knowledge transition from a personal property to the group and creation of additional (tacit and explicit) knowledge from reflection of collaborative 'knowing as action' (p383). The literature review ends with the concept of ambidexterity as a capability (Turner, Swart, Maylor and Antonacopoulou 2016) to evaluate the quality of problemsolving by simulation participants. The methodology section explains the role of simulations in formal education and presents an in-depth description of the case simulation, including processes for critical reflection by participants. Findings are then presented and discussed. The paper closes with a reflection on possible improvements in simulation design and invitation to learned colleagues for further input into this important but under-researched topic. 


\section{Literature Review}

The section starts with the learning and knowledge literature before introducing the knowledge epistemology concept. It ends with a review of the ambidexterity literature on managerial ability to apply exploitative - explorative problem-solving strategies.

\section{Experience, Learning and Sharing}

The assumption that "learning begins with experience" (Argote and Miron-Spektor 2011:1126) finds support in a 20-year longitudinal study of knowledge workers by Kelley (2008) who reported that over $90 \%$ of learning in the organisational context is experiential. Kolb (1984), who has long posited that relationship, defines such experience-oriented learning as "the process whereby knowledge is created through the transformation of experience" (p26). There is considerable evidence that experience accumulates over time (Salas et al 2009)) and repeatedly doing something improves performance (Dutton and Thomas 1994). Experience can also be acquired during or after a task or from a successful or failed intervention (Denrell 2003, 2005). Experience of unusual events such as financial disasters and catastrophic natural or man-made accidents can yield strong learning (Lampel, Shamsie and Shapria 2009). Although theoretical knowledge allows people to develop a view on a given situation by calling upon their store of theories of action, Schulz (2005:494) argues that "learning cannot be divorced from the situation" and any solution must be capable of transforming into knowing action (Dewey 1938 a \& b; Schön 1987).

Another aspect of learning is the importance of interaction for situated or distanced sharing (Bosch-Sijtseman and Henrickson 2014; Gruber, Law, Mandhl and Renkl 1996) and understanding of project complexities (Gheraldi and Niccolini 2000). Innovative thinking occurs when groups of people with common concerns and problems or a passion for a subject can collaborate and learn from one another (Lave and Wenger 1991; Wenger 1998). The ambidexterity literature (below) also supports the idea that experience, knowledge transfer and integration are inextricably related. A caveat to mutual sharing is that experience and learning resides with the individual (Simon 1991). People have to be convinced that there are practical benefits from sharing before they are willing to externalise their tacit knowledge (Nonaka 1994). Akin to that utility argument is the concept of organisational memory, which is created when individuals collaborate to develop group mastery over some organisational routine or task (Cohen and Bacdayan 1994). In line with Lindkvist's (2005) notion of collectives-of-practice, 
Lee-Kelley and Turner's (2017) study of project communities-of-practice confirms the importance of interaction over managerial process for knowledge transfer and coproduction but also observes that the interactions are more goal-oriented, solutionsfocused and transactive.

Of note is Dreyfus and Dreyfus' (1986) differentiation between the experienced actor and the expert. An experienced actor has substantial prior exposure to a range of similar situations and problems. As a result, these actors can draw from their personal store of past successes to guide the search for an executable solution. However, as experience can be difficult to interpret (March 2010) because it has many facets, antecedents and consequences, merely calling upon one's prior experience may not be sufficient for complex problem solving. An expert, according to Dreyfus and Dreyfus, is someone with the added capacity for reflective evaluation. As with the experienced actor, the expert can recall their experience to relate to a new context but will also reflect and evaluate the consequences of results from their past actions. Lessons are internalised and the new knowledge created from both confirmatory and contradictory logics is used to derive a number of alternative strategies (Polanyi 1966). This kind of reflective theory-in-action is contextually relevant (Argyris and Schön 1978) and arguably more suitable for tackling the uncertainties and complexities of projects. The literature implication for educators is the need to ensure PM courses can stimulate individual willingness to collaborate and capacity to improve through practical application and reflection.

\section{Knowledge Epistemologies}

A search was done for papers that can explain the transition of individual experience and knowledge into a group property and how through disciplined productive inquiry, additional knowledge is generated that individuals can take forward to other tasks or situations. The key reference selected for this study is Bridging epistemologies: the generative dance between organizational knowledge and organizational knowing by Cook and Brown (1999). In brief, they accept the traditional distinction between explicit/tacit and individual/group knowledge but argue that possession is key. Explicit knowledge is important as it can help someone to acquire tacit knowledge but it is insufficient in itself to enable someone to perform a task. They view 'action' as behaviour imbued with meaning and 'practice' as action informed by meaning drawn from a particular group context; thus action requires both theoretical knowledge and the ability to apply in context. Findings are discussed around how individuals and their 
groups can draw upon their tacit and explicit knowledge simultaneously, how through situational interaction, a body of knowledge emerges that is held in common by the group and whether that new knowing can support productive problem solving. Their model in Figure 1 clearly delineates knowledge of experience from knowledge from application, and is used in this paper to provide the lens and structure with which to analyse and interpret the case data.

INSERT: Figure 1: Knowledge and knowing-as-action

The four characteristic profiles are distinct but mutually relevant. Each is of equal standing with the others and each performs a function in a way that others cannot. It can also refer to a studied familiarity with PM 'best-practice' guides, tools and techniques, including the need for compliance with published corporate rules and procedures. This type of knowledge is, by its nature, abstract because it is merely about what and how to do rather than actual performance. The latter involves 'work that is done as part of action or practice' (p. 387) which this study seeks to simulate. As Palm and Landahl (2015) indicated earlier, managers do not always start their project role having acquired the requisite knowledge about project management so their decisions and actions may have to be defined through experimentation or from trial and error.

The first box on the left in Figure 1 portrays the epistemology of knowledge possession. This is explained in terms of what is known in one's head (tacit) and that which is acquired through action (explicit). A key argument here is that tacit and explicit knowledge are mutually enabling and can be exercised by individuals and groups in varying ways and measures. Cook and Brown do not accept that tacit knowledge is a hidden, un-actioned form of explicit knowledge (nor the other way around). Borrowing from the American pragmatist movement generally, they argue that individual and group actions should be understood in terms of 'knowledge used in action' and 'knowing as part of action' (p.383). They used the riding of a bicycle as an example to explain that the two epistemologies of tacit and explicit can be used simultaneously by individuals and groups and '.....each form of knowledge can be used as an aid in acquiring the other...' (p.385). In reality, developing the tacit knowledge of riding will require a novice to spend a certain amount of time on a bicycle learning to stay upright. The knowledge of riding is not in the riding itself but something when acquired becomes '.... known by everyone who can ride that most cannot say.' (p.384). This tacit knowledge can help the acquisition of explicit action-oriented knowledge such as comprehending instructions on which way to turn the bicycle handle bars and then actually turning it to 
prevent falling off. This perspective underscores the present study's interpretation of tacit and explicit knowledge acquisition and use.

The middle circle (knowing as action) depicts the application of some combination of tacit and explicit knowledge, individually and severally as a group, to undertake 'real' work or solve a problem. This, they call the epistemology of practice.

The third box illustrates the idea that new personal knowledge will emerge from knowing practice which, through shared enterprise and collective reflection, can produce the kind of collective mind or body of knowledge anticipated by Weick and Roberts (1993). Although the body of knowledge emerging from joint actions may be the property of the group, it need not be known in its entirety by everyone within the group. Their view of within group learning variation may be useful for explaining differences in learning and application in the classroom.

\section{Ambidexterity}

Ambidexterity as a concept has made headway into multiple areas of research including strategy, innovation, technology management and operations management. Turner et al (2016) view ambidexterity as a capability. It reflects the ability of managers to pursue two contrasting objectives (Andriopoulos and Lewis 2010) by referencing and refining existing knowledge while creating new knowledge for alternative solutions for a given task (Turner, Swart and Maylor 2013:320). Exploitation and exploration represent a continuum of ambidextrous strategies. Whereas the driver behind exploitation is an optimising 'quick-win', exploration is a more cautious and sceptical strategy (Klein and Meckling 1958). Exploitation involves scanning for a clear and visible solution that is feasible and quick to implement. During periods of relative stability an incremental exploitative approach can be an efficient choice (Tushman and O'Reilly 1996). When conditions are uncertain or complex, exploitative problem solving may achieve only partial success. These situations will benefit from a less linear and more experimental approach (Turner et al 2016). Lenfle's $(2008,2014)$ research echoes Eisenhardt and Tabrizi's (1995) early advice that in situations of high uncertainty or low problem definition an emphasis on planning and control is counter productive.

Ambidexterity may be temporal (Tushman and O'Reilly 1996), structural (O'Reilly and Tushman 2004) or contextual (Gibson and Birkinshaw (2004). Temporal ambidexterity 
refers to the sequential practice of exploitation then exploration or exploration then exploitation. Resources permitting, managers working on creative tasks or seeking to address opaque problems are better off adopting a more exploratory approach by evaluating a range of alternative options to find the most effective. Trialing and testing options and lessons from other similar projects can also benefit from 'economies of repetition' (Davies and Brady 2000), which can then be utilized as a creative solution in other projects. In a subsequent article Brady and Davies (2004) demonstrated how innovative solutions from 'vanguard' projects (exploration) can be stored and honed over time as a systematic approach to project operations (exploitation). Structural ambidexterity rests on the argument that "exploration and exploitation require substantially different structures, processes, strategies, capabilities and cultures..." (He and Wong 2004: 481). At the team level ambidexterity may be achieved by allocating different roles to each member and the R\&D sub-unit may incorporate standard exploitative administrative functions while the manufacturing group may be trialing novel techniques alongside well-established processes (Gupta, Smith and Shalley 2006). The third mode of contextual ambidexterity is characterized by a combination of stretch, discipline, support and trust behaviours (Gibson and Birkinshaw 2004). The variety of possibilities and options for ambidextrous behaviour and learning has lead Turner et al (2013) to argue there is no single organizational model of ambidexterity. Farjoun (2010) goes further to posit that the key to ambidexterity is one of duality. Studies by He and Wong (2004) and Cao, Gedajlovic and Zhang (2009) have already confirmed that exploitation and exploration may be performed together without trade-off. That is, individuals engaged in routine exercise can indulge in some degree of experimentation and people working on creative tasks will still need routines to some degree. Lindkvist, Söderlund and Tell (1998) share that view, explaining that projects facing the need to generate new knowledge must still work within the scheduled production and budgetary constraints. The idea that exploitation and exploration can occur concurrently in the project context is significant for this study when exploring how project managers might develop the capability to apply one or both effectively. As research on ambidextrous learning at the project managerial action level is still in its infancy (Turner et al 2016; Turner and Lee-Kelley 2013), the findings from this research will enrich the current body of knowledge. 


\section{Research Methodology}

This section presents the learning framework used for the case simulation and describes in detail the profile of participants, the simulation schedule and process.

\section{Learning Framework}

Implicit in the training literature and Schön's reflective practicum $(1983,1987)$ is the idea that people who train together, develop shared schemas that enable them to collectively apply to task. Organised simulations allow participants to work together on some 'meaningful business issues' (Senge, 1990: 21). Simulated problems activate past experiences and assumptions resulting in learning through 'corporate practising' and 'intensive reflection' (Salas et al 2009; Schulz 2005, p453). Rosier, Slade, Perkins et al (2016) fully endorse this form of experiential learning with reference to their own recent study in the education of planners. Figure 2 adapts Kolb, Rubin and Osland's experiential theory (1991) to describe the learning framework for the case simulation.

INSERT: Figure 2: Learning framework for the case simulation

\section{The Simulated Project}

The case simulation is a warehouse construction project (WP). It seeks to create a 'learning laboratory' where participants in their respective teams can 'learn how to learn together' in a 'safe' environment (Senge 1990 p.21). The university has used the WP for many years to support project learning for their MBA, specialist PM master-level programme (MSc PPM) and customised training.

\section{The Simulation Schedule and Process}

MSc PPM simulations are generally held over 3 days and facilitated by a colleague who also assumes the role of project consultant. As researcher, my involvement was as an independent observer. Table 1 below shows the simulation schedule. In line with good teaching practice and the learning framework explained earlier, day 1 begins with a revision on the planning and control tools and techniques previously taught in part 1 of the project planning and control (PAC) module. Experiential learning cycle 1 (LC1) follows with the issue of the WP information booklet. 
INSERT: Table 1: Timetable for the simulated project

The first task for the teams is to develop a strong understanding of the WP scenario and to prepare a plan for execution. Participants may seek clarification on terms, timelines, planning techniques etc. before returning on Day 2 to present their first required output, which is their initial project strategy and plan. Teams are encouraged to question and challenge the assumptions of the presenting group. Actual simulation starts when all the presentations and Q\&A sessions are completed. The first 8 iterations of the WP allow participants to acquaint themselves with the practical aspects of performing the simulated project and to 'test' their existing knowledge and experience on the initial problems. Task 2 requires that teams undertake their first debrief and reflect on their interim results. Having discussed their performance, updated their project status and considered how they would prepare for day 3 , teams present their revised plan (output 2) and receive feedback from the facilitator and other teams.

Simulation resumes on day 3 when the facilitator introduces a series of 'unexpected' events and tightens iteration lead times to stimulate pressure and pace, and to test participants' responses. A final debrief and reflection session (task 3) takes place when all 5 teams have completed their project. Teams return to present their group and individual lessons (output 3a). Day 3 ends with the facilitator reviewing teams' performances against the average of prior MSc cohorts. This is followed by an open discussion of the lessons that can inform future practice. Output $3 \mathrm{~b}$ is a written group essay due 2 weeks after the simulation. Teams are required to detail their learning applications supported by specific examples of altered decisions and behaviours, including the impact on the team's performance. Finally, every participant has to identify some key personal 'takeaways' for application back in their respective organisations.

\section{The Participants}

A database of simulation results and personal and group reflections have accumulated over 10 cohorts of the Master in Programme and Project Management (MSc PPM). Data from 5 teams representing a single cohort is presented here as an illustrative case. The agreed capacity for this centrally funded MSc PPM at the time was 25. Cohort X (CX, for confidentiality and security reasons) comprised 15 military officers (5 Navy, 5 Army, 5 RAF), 5 defence civilians and 5 managers from industry. The structured process of military boarding and academic selection means student profiles for the MSc PPM were 
pretty homogenous. All CX students were operating at middle-management level (i.e. army major equivalent), aged around late $30 \mathrm{~s}$ to mid $40 \mathrm{~s}$ with at least 8 years of 'relevant' involvement in projects or operations requiring planning and management. Nearly all had at least an Association for Project Management Practitioner (APMP) Certificate.

\section{Findings}

The 'hard' results are first reported because every decision about a project and its management has a financial consequence. A chronology of the simulation by learning cycles tracing knowledge and learning transition is then presented by reference to Cooke and Brown's (1999) epistemological flow. Sources of data for determining participant learning and knowledge transition include direct observation, access to the WP simulation requirements and computer-generated status sheets, teams' PowerPoint presentations and their final written reflective essays, including images captured during the simulation (by the researcher).

\section{'Hard' Performance Results}

In order to complete each task and eventually the project, members had to agree the priority in which to allocate and schedule task resources. The line graphs in Figure 3a depict the initial, revised and final profit (or loss) for Cohort X teams. The bar charts in Figure $3 \mathrm{~b}$ show projected and final completion weeks. Briefly, Team 1 (Army) was the clear 'winner' of that competition.

INSERT: Figure 3a: Project $€$ profit/(loss)

INSERT: Figure 3b: Project completion (weeks)

They completed their project by the end of week 18 at a final profit of $£ 78 \mathrm{k}$. Team 2 (Navy) faired less well, completing in week 21 and making a loss of $-£ 43 \mathrm{k}$. Team 3 (RAF) was the runner-up team being only a week behind Team 1 at 19 weeks with a modest profit of $£ 26 \mathrm{k}$. Team 4 (MOD civilians) suffered the biggest loss at $-£ 57 \mathrm{k}$ and took the longest to complete the project (24 weeks). Ironically, of the three teams who had suffered acute cost overruns, two of them (T4 and T5) came to the simulation with greater direct project experience than the other 3 military teams. 
To ascertain the literature's assumption of beneficial effects from prior PM experience and learning, the CX case results were validated against the simulation results from previous MSc PPM cohorts and compared with average performances by the full-time and part-time executive MBA programmes in the same year. Given the common entry requirements, age, rank and work experience across MSc PPM cohorts, it is understandable that CX's results profile should be similar to other MSc PPM cohorts. On the other hand, as CX students are on a specialist PM course and have greater PM experience than the MBAs, comparison between them reflected the assumption that MSc students would fair better than the MBAs: CX Team 1's profit of $£ 78 \mathrm{k}$ was well ahead of the average MBA profit of $£ 46 \mathrm{k}$, and CX Team 4's loss of - $€ 57 \mathrm{k}$ was comfortably less than the poorest performing MBA team, which stood at $-£ 159 \mathrm{k}$.

\section{Learning and Knowledge Transition}

Day 1 Experiential Learning Cycle 1 (LC1): Direct observation of group discussions and decisions trade-offs found participants actively engaging their personal experience (tacit) and their taught (explicit) knowledge about projects to scrutinise the Warehouse Project (WP). Teams defined terms, constructed the WP network diagram and compiled a list of required resources and their associated costs and lead times, including agreed 'decision rules'. With that in place, they worked quickly to develop a theory-of-action on how best to deliver their project and reported to the facilitator with their initial project plan. The Q\&A session at each presentation extracted further detailed explanations, assumptions and logical arguments for planning choices and trade-offs.

Day 2 Experiential Learning Cycle 2 (LC2): Teams confirmed their readiness for the simulation by generating their first formal resources requirement request on the morning of day 2. By the end of iteration 3, it was clear that teams had learnt and assimilated much of the workings of the simulated project. All were able to submit their next iteration request promptly. Participants appeared highly motivated. Photographic images taken by the researcher from day 2 showed some members scrutinising the computer-generated action report (project status sheet) and trying to drill down to the root of deviations while others were working to update their resource and schedule masters. Project status and issues were displayed clearly on the walls of breakout 
rooms alongside earlier fact-finding and planning postings. Although teams were reminded that given the small team size every member should have a secondary role, it was noted that cash flow tended to be managed by a dedicated member and generally on the computer (against the facilitator's advice). As a result, financial control was not as visible to others in the team. At the close of LC2, presentations were made of revised plans and logged by the facilitator. Challenging questioning during Q\&A on the impact of early errors and omissions on project outcomes and what steps were taken to avoid repeating the mistakes forced teams to articulate the basis for their revised strategies. An early summation at this stage of the simulation is that the opportunity to work 'in safety' on a realistic but not too complex scenario enabled situated appraisal and group learning.

Day 3 Experiential Learning Cycle 3 (LC3): Day 3 tested how participants might use their new, expanded knowledge to overcome unexpected problems and issues. The allocated times between iterations were deliberately shortened. Two major unknownunknown events were introduced to the CX project at the $10^{\text {th }}$ and $12^{\text {th }}$ iterations: the team member responsible for finance and cash flow management was declared 'ill' for three periods followed by a supply disruption owing to the liquidation of a supplier before completing their contracted delivery of a key component. Removal of a single member represented a $20 \%$ reduction in capacity and the finance function was a pivotal role owing to the (noted) practice of a dedicated resource. Liquidation of the contractor required immediate schedule and cost impact review. This had to be done by the remaining members while having to adjust to the reduced iteration turnaround times. The impact of the events on team performance was negative and immediate. Their severity may be seen in Figures 4a. The cost distance between revised and final worsened across the board, particularly for Teams 2 and 5. Team 1 was least affected but they still returned a lower profit than anticipated. Team 2's combined PM knowledge was very limited and operational pressures meant the team was not working to full strength most of the time during the simulation. This could explain their poor performance. Team 3's attributed their 'performance gap'to a number of human errors and omissions. These were indeed evident from their action reports. Team 4 concluded that while they had the knowledge and know-how they lacked the confidence to take risk or empower themselves to lead change even in a 'safe' environment. Given the hierarchical nature of Defence, this may be a credible explanation. Team 5 comprised of defence contractors with the most PM experience and knowledge. They accepted their 'change execution strategy was weak' particularly their speed of adjustment, detail of 
allocation of resources to task, poor time management and slow deciphering of action reports. The lack lustre performances (T4 and T5 particularly) are paradoxical somehow, participants were unable to execute their logically defended corrective strategies.

\section{Discussion and Conclusion}

The aim of the WP simulation is to encourage reflective practice by providing participants the opportunity to work as a team to derive 'common' solutions; evaluate the outcomes and efficacies of their mutual enterprise against system generated status reports (provided to the teams after each iteration); ascertain explanatory lessons that will guide the development of alternative theories for action and apply the preferred solution. CX's results in figures $4 \mathrm{a} \& 4 \mathrm{~b}$ are perplexing in that all 5 teams struggled to deliver their project despite ample opportunities for reflection and review of their delivery strategies. To understand the phenomenon, I will start with a chronological scrutiny of the simulation's pedagogical assumptions, process and anticipated learning outcomes.

It was explained in the Research Methodology that the 3-day schedule for the MSc programme would adhere to the experiential learning framework inspired by Kolb (1984), Kolb et al (1991) and Senge (1990). As a non-participatory researcher who observed the entire simulation, I am satisfied that was the case. Although the simulation permitted the facilitator to alter situational complexity, manipulations were in line with the literature; namely, that learning happens with doing (Denrell 2003; 2005); repetition yields proficiency (Dutton and Thoms, 1994; Salas et al 2009) and unexpected events can induce innovative responses and strong learning (Lampel et al 2009). Running the 'vanilla' version over 8 weeks allowed participants to develop the necessary situational awareness and practise moving theory into 'concrete action' (Cook and Brown 1999, p.387). The subsequent tightening of simulation rotations and introduction of unexpected events during LC3 had been effective; requiring teams to take stock, explore options and select solutions. Debriefing guidance given to participants followed the literature advice that debriefs should encourage actors to engage in deep and meaningful discussions of their experience, draw lessons and develop alternative options which can they put into active experimentation. In addition, 
required outputs from each debrief sessions were clearly designed to support participant transition from experienced practitioners who know-what-to-do to reflective experts with flexible and transferable skills (Dreyfus and Dreyfus 1986). In the light of the discussion, the case simulation's structural and process assumptions are well founded and unlikely to be responsible for CX's performance anomaly.

Interrogation of the anticipated learning outcomes (LO) revealed three categories: (1) knowledge and understanding, (2) cognitive and intellectual awareness and (3) practical application and transferable skills. Their realisation may be surmised through Cook and Brown's (1999) knowledge epistemologies: personal tacit knowledge gained from prior experience and explicit taught learning from the MSc Programme (including other PM training courses) enable theoretical understanding and intellectual awareness of participants to develop a view on their given situation (LO1 and LO2). When integrated as group cognition, teams can collaborate to derive a joint plan of action which, when enacted as reflective action (Dewey 1938 a \& b; Schön 1987) is a demonstration of L03. However, findings suggest that although participants demonstrated the first two LOs successfully and observational summation at the close of day 2 had identified the co-production of actionable knowledge (i.e. teams making sense of their situation, devising their project strategy and creating their plan for action), LO3 was only met in part because participants were slow to transit as experienced actors to reflective experts (Dreyfus and Dreyfus 1986). Team 5 was a particularly striking example.

I turn to the ambidexterity literature to illuminate the missed opportunities by participants to turn knowledge into effective practice. Ambidexterity is seen as a managerial capability (Turner et al 2016). If teams had achieved all 3 LOs, they would have been able to decipher a situation, generate a plan of action and carry out their plan by employing a range of ambidextrous (exploit-explore) strategies (Tushman and O'Reilly 1996; Farjoun 2010). The findings indicate that was not the case. Figure 4 is a diagrammatic representation of ambidextrous opportunities in the case simulation.

INSERT: Figure 4: Opportunities for Ambidextrous Solutions

The dotted arrow depicts ambidexterity as a capability with two modes: exploitation and exploration (horizontal axis). The vertical axis reflects the extent of exploitation 
and/or exploration. The 3 simulation learning cycles are inserted as arcs within the axes to illustrate how ambidextrous application might be beneficial.

LC1 was about fact-finding, context setting and preparation for performance. At this stage, there would be little additional information and performance data had yet to be generated. Therefore as experienced participants, members would exploit their existing experiences and knowledge to develop a strong understanding of the project objective, discover limitations and constraints, make assumptions related to the wider environment surrounding the project and develop their initial plan of action. LC2 required teams to action their initial plan; stop, reflect and draw lessons to develop a revised (improved) plan of action. Both time and complexity pressures during this period were low as the facilitator had yet to introduce unexpected events. LC2 was a stable state for which, according to the ambidexterity literature, an incremental exploitative approach would suffice (Tushman and O'Reilly 1996). Nonetheless, within the 'safe' environment of the MSc in general and the case simulation specifically, student participants could have taken the opportunity to include a small measure of experimentation (exploration) while continuing to scan for 'quick-wins' and adjusting affected items within the schedule and cash flow (exploitation). Taking time to explore future risks and plan for their mitigation would have helped teams to be better prepared for unexpected events. However, Team 4's reluctance to take risk and Team 5's inflexibility from over-confidence would suggest that process alone is insufficient to engender attitudinal or behavioural change.

When disruption and uncertainty happened in LC3, teams no longer have the time to explore or test alternative solutions. Even when Team 4 had the initiative to seek compensation for the disrupted supply and was appropriately recompensed, they could not correct the negative impact on their schedule. Contrary to the literature's caution that when conditions are uncertain or complex, it is risky to rely on hard facts and strict planning and control techniques (e.g. Eisenhardt and Tabrizi 1995, Lenfle 2008) teams continued to look for obvious solutions because they felt compelled to keep to a tight schedule.... stay on mission' (T1) and to finish 'as early as possible' (T3). Others concluded that the simulation was incredibly fast moving' (T4) and 'too tight and unrealistic' (T5), eventually 'accepting defeat' and stopped trying all together. These cognitive and behavioural biases were not but should have been factored into the simulation design. 
In conclusion, although the pedagogical foundations for the case simulation are sound and its structure and process robust, discussion of findings has identified sociopsychological and contextual reasons for the apparent struggle. Looking back to previous cohorts' reflections, time compression, manual working and project finance were also common problematic themes. I offer a number of recommended changes to increase managerial capability and reduce the perceived teaching-doing gap:

1. Explicit learning outcomes for each learning cycle: As the simulated project is a component of the planning and control (PAC) module, the LOs reviewed are generic to the module. While they allow a high-level evaluation of learning achievements (as I have done in the findings and discussion) LOs should be specific to the simulation with sub-LOs defined for each learning cycle particularly as regards their ambidextrous learning and application (see Figure 5). Manipulations by the facilitator may then be implemented with that in mind. Simulation-level LOs will make its purpose and object more transparent and students will be more aware of the learning and change expected of them.

2. Incorporate technology: Manual working was a common attributed barrier to rapid communication and information management, ultimately slowing decisions and corrective actions. Social media is very much part of $21^{\text {st }}$ century private and business lives therefore it makes little sense to insist that students toil through their simulation without computing aid. Modernising the simulation process by allowing the use of PM software (such as scheduling, risk and cash management) should ease project changes and updates and help participants keep pace with iteration lead times.

3. Project finance and cash flow management. The WP simulation already recognises that project costing and finance is a critical task. Aside from various direct costs (e.g. labour, staff accommodation, cranes and building materials) there are additional indirect costs in the form of stockholding, insurance, consumables and a weekly project overheads charge. Although teams can apply for either an overdraft or a fixed term loan, cost of borrowing requires teams to carefully balance their payables with progress receivable to avoid default. However, the adverse and prolonged impact on team performance when the team member responsible for financial and cash flow management was removed temporarily for health reasons, suggests an inherent weakness which requires 
urgent attention. Protracted struggling by teams (e.g. Teams 4 and 5) resulted in lost of interest and drive. A review and mapping of that particular aspect of the simulation to the project financial control component within the MSc programme and the PAC module is recommended. Students with little or no direct finance experience should be given the opportunity to acquire the theoretical knowledge (at the least) to bring to the simulation. Increased understanding and awareness coupled with the ability to utilise modern PM tools should reduce participant frustration and improve problem analysis and decisions.

4. Repetition for learning reinforcement. Speed of simulation was also identified as a barrier, particularly in LC3. Recalling Davies and Brady's (2000) idea of economies of repetition and Cook and Brown's (1999) notion of productive inquiry, the PAC module structure should be revised to include a repetition of the same simulation (after a short break). This will allow students to consciously apply and test lessons from the previous exercise.

In closing, I return to the paper's question of "how easily is knowledge developed in the classroom transformed into effective practice?" The answer is 'not easily'. The study using pre-experienced individuals has shown that transition from merely knowing-what to effective practice is not straightforward. It has led the way by referencing the ambidexterity literature to illuminate how opportunities for greater flexibility and more ambidextrous solutions could be built into the learning outcomes. However, it has also found that developing the ability to think 'outside the box' requires more than a robust structure or sound process. As indicated by the case simulation, there is a myriad of possible barriers and attributions for failure (e.g. human error, speed, confidence, manual working and project finance). Current teaching models rarely take into account the 'soft' perceptions and behavioural responses of students. Aside from the need to revisit our assumptions on how learning can be designed and realised, there is also the need to understand why people fail to convert their learning into effective practice. I very much hope that my academic colleagues can provide further insights on this important but as yet, under-researched topic. 


\section{References}

- Andriopoulos, C. and Lewis, M. W. (2010) Managing innovation paradoxes: ambidexterity lessons from leading product design companies. Long Range Planning $43,104-122$

- Alam, M., Gale, A., Brown, M. and Kidd, C. (2008) The development and delivery of an industry led project management professional development programme: A case study in project management education and success management, International Journal of Project Management, 26, 223-237

- Argote, L. \& Miron-Spektor, E. (2011) Organizational learning: From experience to knowledge. Organization Science, 22, 5, p1123-1137

- Argyris, C. and Schön, D. (1978). Organizational Learning: A Theory of Action Perspective, Addison-Wesley, Reading, MA.

- Berggren, C. and Söderlund, J. (2008) Rethinking project management education: Social twists and knowledge production, International Journal of Project Management, 26, 286-296

- Bosch-Sijtseman, P.M. and Henrickson, L-H. (2014). Managing projects with distributed and embedded knowledge through interactions, International Journal of Project Management, 32, 8, 1432-1444

- Boyer, E.L.(1992) Scholarship reconsidered: Priorities of the professoriate, Issues in Accounting Education, 7, 1, 87-91

- Brady, T. and Davies, A. (2004) Building project capabilities: from exploratory to exploitative learning. Organization Science, 25, 9, 1601-1621.

- Cheetham, G. and Chivers, G. (2001). Part II - How professionals learn - the practice! What the empirical research found, Journal of European Industrial Training, 25, 5, 248-292

- Cao, Q., Gedajlovic, E. and Zhang, H. (2009) Unpacking organizational ambidexterity: dimensions, contingencies and synergistic effects. Organization Science, 20, 781796.

- Cohen, M.D. and Baccdayan, P. (1994) Organizational routines are stored as procedural memory. Evidence from a laboratory study. Organization Science, 5 (4), 54-568

- Cook, S.D.N. and Brown, J.S. (1999). Bridging epistemologies: The generative dance between organizational knowledge and organizational knowing, Organization Science, 10, 4, $381-400$ 
- Crawford, L., Morris, P., Thomas, J. and Winter, M. (2006). Practitioner development: from trained technicians to reflective practitioners. International Journal of Project Management, 24, 722-733.

- Cummings, T.G. and Jones, Y. (2004) Conference theme: Creating actionable knowledge. Academy of Management Website: http://meetings.aomonline.org/2004/theme.htm, 1-4

- Davies, A. and Brady, T. (2000) Organisational capabilities and learning in complex product systems: towards repeatable solutions. Research Policy, i29, 7, 931-953

- Denrell, J. 2003. Vicarious learning, undersampling of failure, and the myths of management. Organization Science 14, 3, 227-243.

- Denrell, J. 2005. Should we be impressed with high performance? Journal of Management Inquiry 14, 3, 292-298.

- Dewey, J. (1938a) Experience and education. MacMillan, New York.

- Dewey, J. (1938b) Logic. The theory of inquiry. Henry Holt \& Company, New York.

- Dreyfus, H.L. and Dreyfus, S.E. (1986) Mind over machine. The power of human intuition and expertise in the era of the computer, Free Press, New York.

- Dutton, J. M., A. Thomas. 1984. Treating progress functions as amanagerial opportunity. Acad. Management Rev. 9, 2, 235-247.

- Eisenhardt K.M. and Tabrizi, B.N. (1995) Accelerating adaptive processes: product innovation in the global computer industry. Administrative Science Quarterly, 40, 1, 84-110

- Farjoun, M. (2010). Beyond dualism: stability and change as duality. Academy of Management Review, 35, 202-225.

- Gibson, C.B. and Birkinshaw, J. (2004) The antecedents, consequences and mediating role of organizational ambidexterity. Academy of Management Journal, 47, 2, 209226

- Gruber, H., Law, L-CH., Mandl, H. and Renkl, A. (1996) "Situated learning and transfer" Interdisciplinary Learning Science, Elsevier Science, Oxford, p168-188.

- Gupta, A.K., Smith, K.G. and Shalley, C.E. (2006) The interplay between exploration and exploitation. Academy of Management Journal, 49, 4, 693-706.

- Hallinger and Bridges 2007. Preparing managers for action. Spinger, Dordrecht.

- He, Z. and Wong, P. (2004). Exploration vs. Exploitation: an empirical test of the ambidexterity hypothesis. Organization Science, 15, 4, 481-494

- Kelley, R. (2008), Longitudinal Study with Knowledge Workers, Carnegie Mellon, Pittsburgh, PA. 
- Klein, B. and Meckling, W. (1958) Application of operations research to development decisions. Operations Research, 6, 3, 352-363

- Kolb, D. 1984. Experiential learning: experience as a source of learning. New Jersey: Prentice Hall.

- Kolb, D.A., Rubin, I.M., and Osland, J.S. 1991. Organizational behavior: an experiential approach. Englewood Cliffs, NJ: Prentice Hall.

- Lampel, J., Shamsie, J. and Shapira, Z. (2009) Experiencing the improbable; rare events and organizational learning. Organization Science, 20, 5, 835-845

- Lave, J. and Wenger, E. (1991) Situated learning: Legitimate peripheral participation, Cambridge University Press, Cambridge.

- Lee-Kelley, L. and Turner, N. (2017) PMO managers' self-determined participation in a purposeful virtual community-of-practice, International Journal of Project Management, 35, 64-77

- Lenfle, S. (2008). Exploration and project management. International Journal of Project Management, 26, 5, 469-478

- Lenfle, S. (2014). Toward a genealogy of project management: Sidewinder and the management of exploratory projects. International Journal of Project Management, $32,6,921-931$

- Lindkvist, L (2005) Knowledge communities and knowledge collectives: a typology of knowledge work in groups. Journal of Management Studies, 42,6, 1189-1210.

- Lindkvist, L. Soderlund, J. and Tell, F. (1998) Managing product development projects: on the significance of fountains and deadlines. Organization Science, 19, 6, 931-951

- March, J.G. (2010), The Ambiguities of Experience, Cornell University Press, Ithaca, New York, NY.

- Nonaka, I. (1994) A dynamic theory of organizational knowledge creation. Organization Science. 5(1).

- O'Reilly, C.A. and Tushman, M.L. (2004). The ambidextrous company. Harvard Business Review, 82, 4, 74-81

- Palm, K. and Lindahl, M. (2015). A project as a workplace - Observations from project managers in four $\mathrm{R} \& \mathrm{D}$ and project-intensive companies, International Journal of Project Management, 33, 828-838

- Polyani, M. (1966) The tacit dimension. Routledge, London

- Project Management Institute (2013). A guide to the project management body of knowledge (PMBOK Guide) $5^{\text {th }}$ Ed. Pennsylvania, USA. 
- $\quad$ Rosier, J., Slade, C., Perkins, T., Baldwin, C., Coiacetto, E., Budge, T. and Harwood, A. (2016). The beneifts of embedding experiential learning in the education of planners, Planning Practice \& Research, 31, 5, 486-499

- Salas, E., Wildman, J. and Piccolo, R. 2009. Using simulation-based training to enhance management education. Academy of Management Learning \& Education, 8, 4:559-573.

- Savelsbergh, C.M.J.H., Havermans, L.A. and Storm, P.M. (2016) Development paths of project managers: What and how do project managers learn from their experiences? International Journal of Project Management, 34, 559-569

- Schön D.A. (1983) The Reflective Practitioner: How Professionals Think in Action, Basic Books, New York

- Schön D.A. (1987) Educating the reflective practitioner: Toward a new design for teaching and learning in the professions. Jossey-Bass, San Fransico.

- Schön D.A. (1995) The new scholarship requires a new epistemology, Change, 27, 6, $27-34$

- Schulz, K-P (2005) Learning in complex organizations as practicing and reflecting: a model development and application from a theory of practice perspective. Journal of Workplace Learning, 17, 7/8, 493-507

- Senge, P.M. (1990). Catalysing systems thinking within organisations In Massarik, F. (ed) Advances in Organizational Development, Vol 1. Ablex, Greenwich, CT, 197-246

- Simon, H.A. (1991) Bounded rationality and organizational learning. Organization Science, 2(1).

- Starkey, K. and Madan, O. (2001). Bridging the relevance gap: aligning stakeholders in the future of management research, British Journal of Management, 12 (special issue), S3-S26.

- Turner N and Lee-Kelley L (2013) Unpacking the theory on ambidexterity: An illustrative case on the managerial architectures, mechanisms and dynamics. Management Learning 44, 2,179-196.

- Turner, N., Swart, J. and Maylor, H. (2013) Mechanisms for managing ambidexterity: a review and research agenda. International Journal of Management Review, 15, 317-332

- Turner, N., Swart, J., Maylor, H. and Antonacopoulou, E. (2016) Making it happen: how managerial actions enable project-based ambidexterity, Management Learning, $47,2,199-222$ 
- Tushman, M.L. and O’Reilly , C.A. (1996) Ambidextrous organizations: managing evolutionary and revolutionary change. California Management Review, 38, 4, 8-30

- Weick, K.E. and Roberts, K.H. 1993. Collective mind in organizations: heedful interrelating on flight decks. Administrative Science Quarterly, 38: 357-381.

- Wenger, E. (1998). Communities of practice: learning, meaning and identity. Cambridge University Press, Cambridge.

- Winter, M., Smith, C., Morris, P. and Cicmil, S. (2006). Directions for future research in project management: the main findings of a UL government funded research network. International Journal of Project Management, 24, 638-649. 
Paper: When 'Knowing What' is not Enough: Role of Organised Simulations for Developing Effective Practice

\section{FIGURES}

Figure 1: Knowledge and knowing-as-action

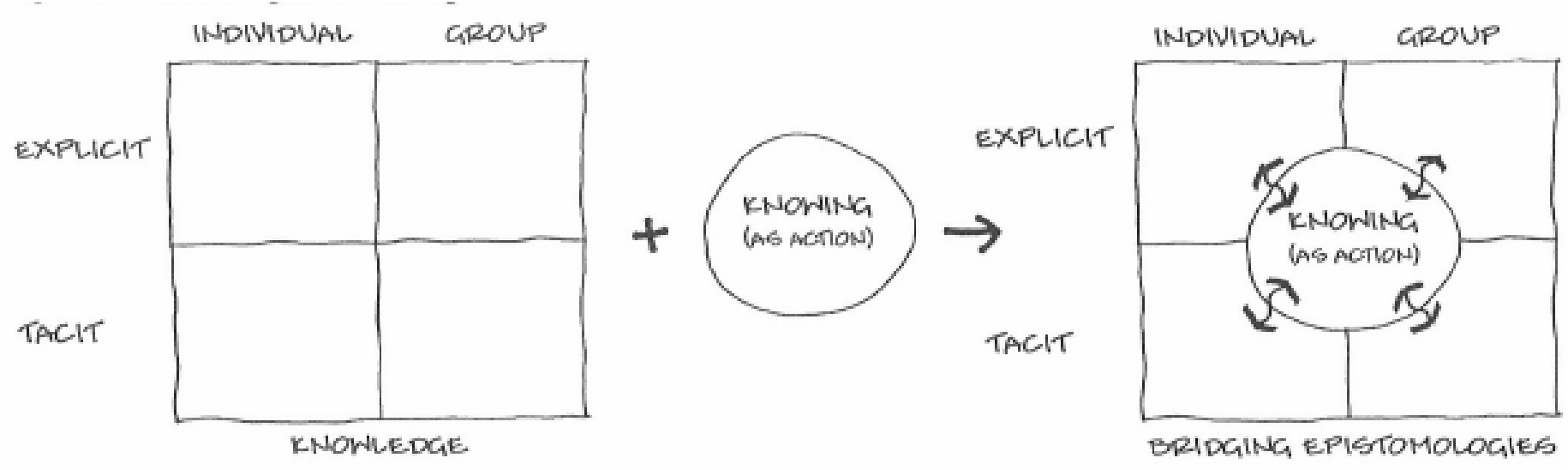

Source: Cook and Brown (1999 p.383)

Figure 2: Learning framework for the case simulation

\section{Individual Experience and Knowledge}
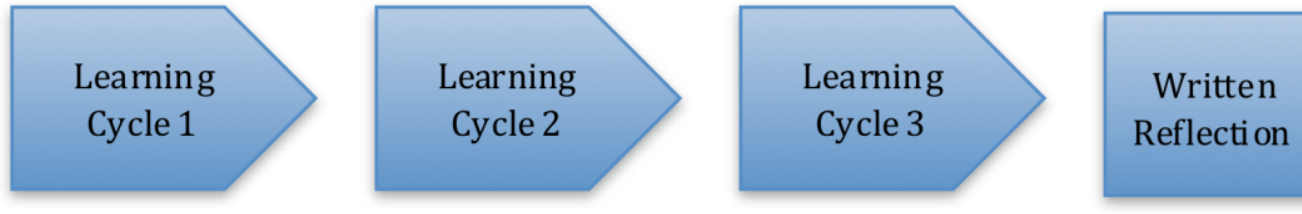
Figure 3a: Project $£$ profit/(loss)

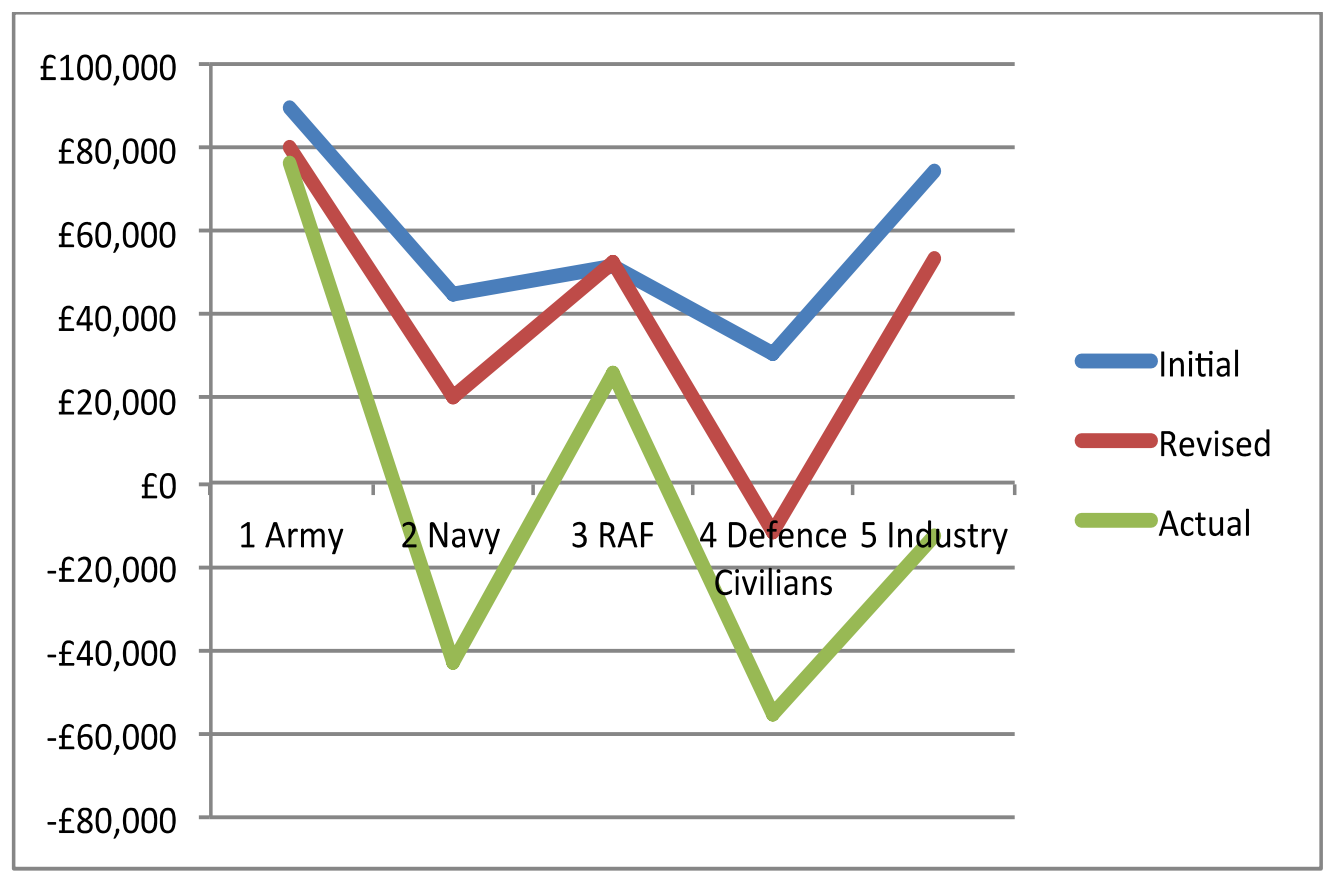

Figure 3b: Project completion (weeks)

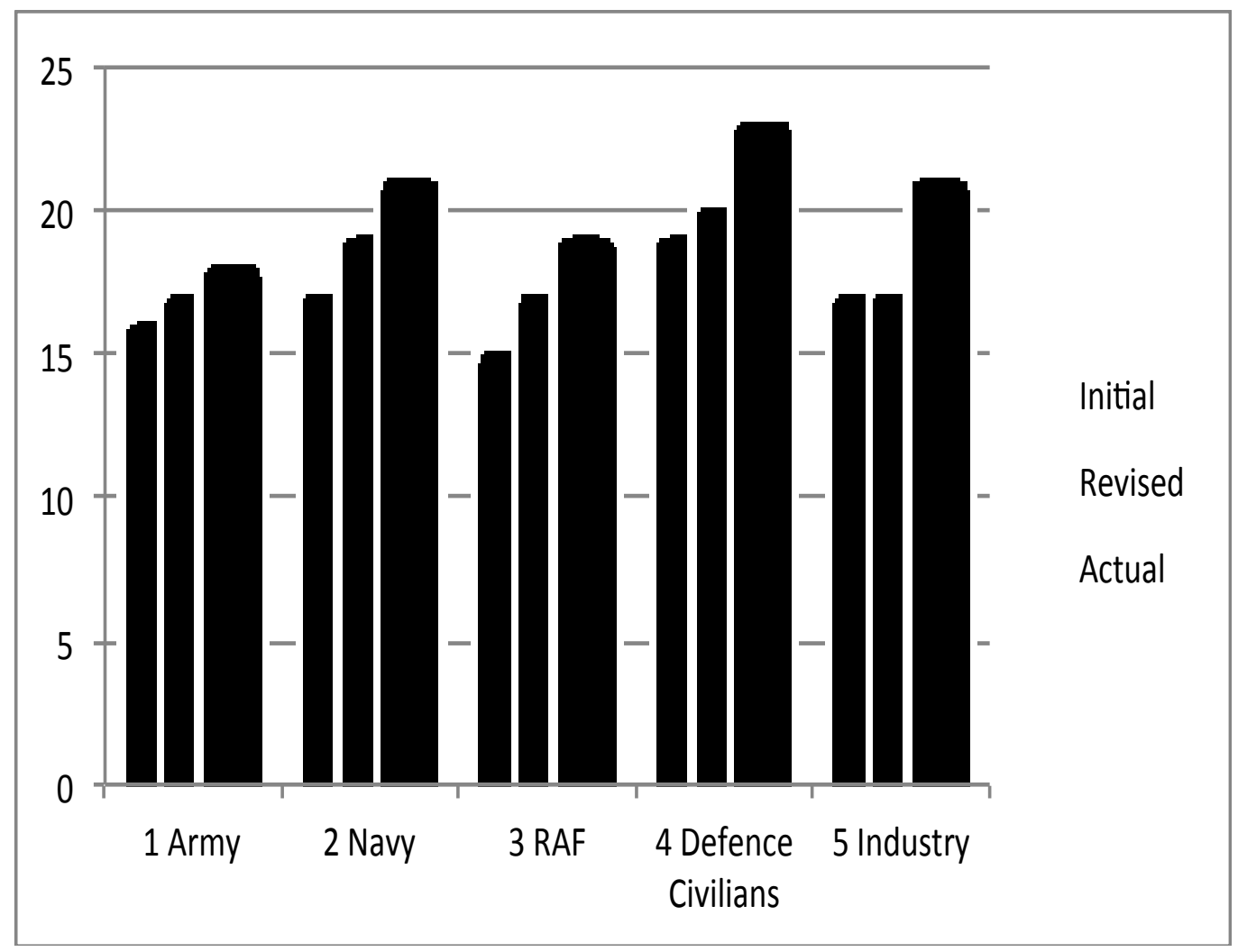


Figure 4: Opportunities for Ambidextrous Solutions

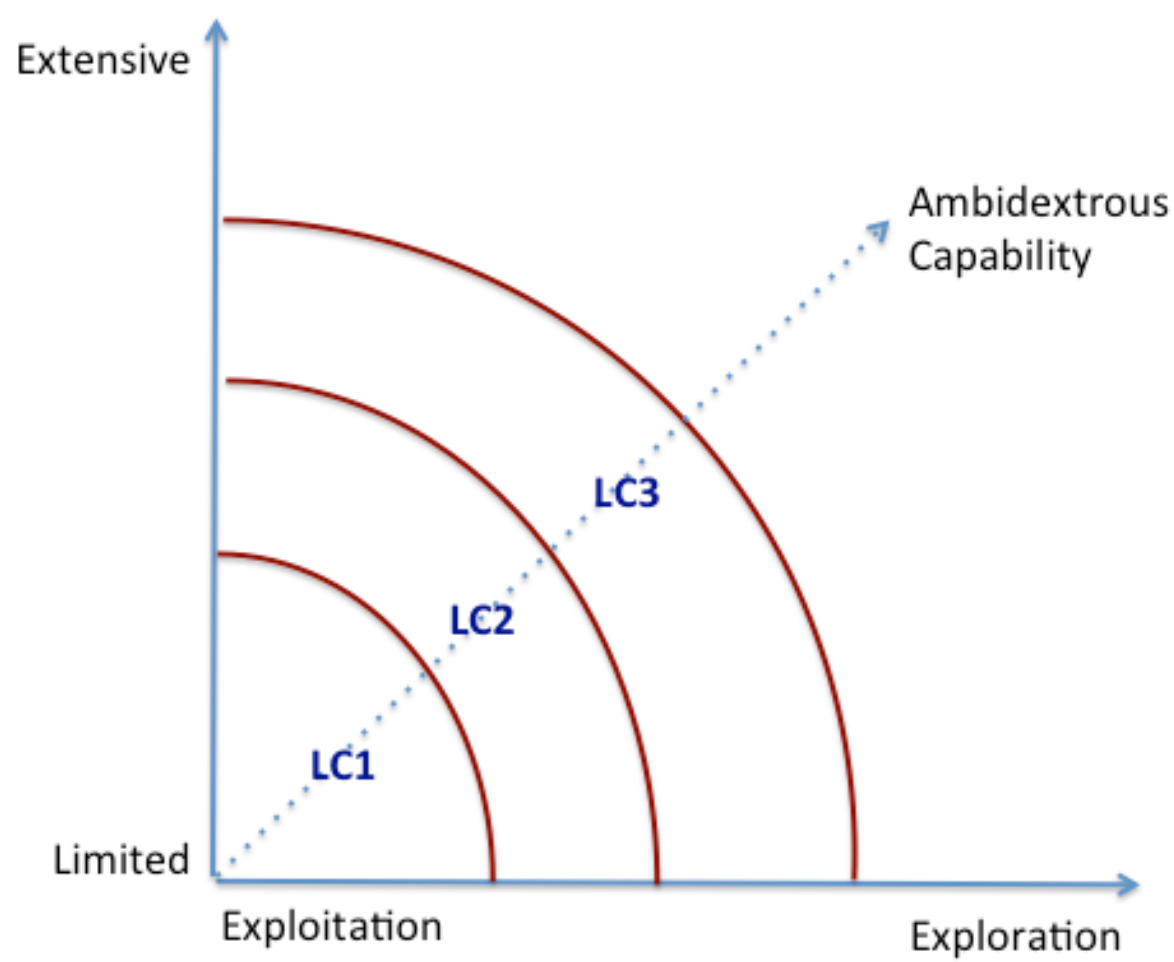

$L C 1, L C 2, L C 3=$ Learning Cycles 1, 2 \& 3 
Paper: When 'Knowing What' is not Enough: Role of Organised Simulations for Developing Effective Practice

\section{Tables}

Table 1: Timetable for the simulated project

\begin{tabular}{|l|l|l|}
\hline Day 1 & a.m. & Revision on fundamentals \\
\hline & p.m. & $\begin{array}{l}\text { Experiential Learning Cycle 1 } \\
\text { Issue of simulation booklet } \\
\text { Simulation briefing } \\
\text { Task 1 - Team preparation }\end{array}$ \\
\hline Day 2 & a.m. & $\begin{array}{l}\text { Output 1 - Team presentations (initial plan) } \\
\text { Simulation starts }\end{array}$ \\
\hline & p.m. & $\begin{array}{l}\text { Experiential Learning Cycle 2 } \\
\text { Simulation pauses } \\
\text { Task 2 - Team debriefing \& reflection (interim results) } \\
\text { Output 2 - Team presentations (revised plan) }\end{array}$ \\
\hline Day 3 & a.m. & $\begin{array}{l}\text { Experiential Learning Cycle 3 } \\
\text { Simulation resumes } \\
\text { Facilitator introduces 'unexpected' events }\end{array}$ \\
\hline & p.m. & $\begin{array}{l}\text { Task 3 - Team debriefing \& reflection (final results) } \\
\text { Output 3a - Final presentations (lessons) }\end{array}$ \\
\hline & & Output 3b - Team reflective essay, 2 weeks later (assessed) \\
\hline
\end{tabular}

